\title{
Early Identification of Autism: How Early Can We Go?
}

\author{
Elizabeth R. Crais, Ph.D., 1,5 Linda R. Watson, Ed.D.,, ${ }^{2,5}$ Grace T. Baranek, Ph.D.,, 3,5 \\ and J. Steven Reznick, Ph.D.,
}

\section{ABSTRACT}

Identification of young children at risk for Autism Spectrum Disorders (ASD) depends on early behavioral symptomatology and yet conventional criteria provide little guidance for use with infants and toddlers. Recent research, however, has demonstrated that there are patterns of behavior below 2 years of age that distinguish children with autism from those who are developing typically or those with other developmental disabilities. Skill areas with particular promise for early identification include social communication, sensory regulation, and play. This article previews current innovative methodologies, presents a synthesis of recent research findings related to these three key areas, and provides clinicians with practical guidelines for early identification of infants and toddlers at risk for ASD and other disorders.

KEYWORDS: Autism spectrum disorders, infants and toddlers, early identification

Learning Outcomes: As a result of this activity, the reader will be able to (1) describe recent methodologies for investigating patterns of behavior in infants and toddlers that place them at risk for later diagnosis of autism; (2) explain the importance of the areas of social communication, sensory regulatory, and play to early identification; and (3) discuss practical strategies for early identification of infants and toddlers at risk for autism spectrum and other disorders.

The prevalence of Autism Spectrum Disorders ${ }^{1}$ (ASD) has increased over the past 30 years, and recent data in the United States indicate that 5.5 to 5.7 children $^{\mathrm{Q} 1}$ are likely to be identified as having ASD. ${ }^{1}$ Some of the reasons cited for the increases are the enhanced awareness of ASD and the broadening of diagnostic criteria that have led to improved

\footnotetext{
${ }^{1}$ Professor, Division of Speech and Hearing Sciences, ${ }^{2}$ Associate Professor, Division of Speech and Hearing Sciences, ${ }^{3}$ Associate Professor, Division of Occupational Sciences, ${ }^{4}$ Professor, Department of Psychology, ${ }^{5}$ University of North Carolina at Chapel Hill, Chapel Hill, North Carolina.

Address for correspondence and reprint requests: Elizabeth R. Crais, Ph.D., Division of Speech and Hearing
}

Sciences, University of North Carolina at Chapel Hill, Chapel Hill, NC ${ }^{\mathrm{Q} 30}$. E-mail: bcrais@med.unc.edu.

Current Issues in Providing Services to Infants and Toddlers; Guest Editor, Elizabeth R. Crais, Ph.D.

Semin Speech Lang 2006;27:143-160. Copyright (C) 2006 by Thieme Medical Publishers, Inc., 333 Seventh Avenue, New York, NY 10001, USA. Tel: +1(212) 584-4662. DOI 10.1055/s-2006-948226. ISSN 0734-0478. 
identification of these children. ${ }^{2}$ In addition, increases of children with ASD served under the Individuals with Disabilities Education Act (IDEA) have been reported across many states. ${ }^{3}$ And yet within the United States, no states are reporting as high a number of children entering the early intervention system as would be expected from the US prevalence data. ${ }^{4}$ Moreover, prevalence figures in European countries are even higher (closer to 6 per $10,000^{\mathrm{Q} 2}$ children $)^{5}$ perhaps because of the increased ability in these countries to monitor children's growth and risk status through the health-care system. Thus, we must ask ourselves whether practitioners in the United States are identifying all the children who are at risk for autism, and are we doing so at an early enough age for these children to benefit optimally from early intervention? Throughout this article, we will use "autism" to refer broadly to disorders in the autism spectrum.

Despite changes in diagnostic criteria and increased awareness of ASD in the United States, we continue to identify most children with ASD between 3 and 4 years of age, with relatively few children identified under 3 unless their symptoms are severe (e.g., they lack language or have very odd mannerisms) and they have been referred to a specialty clinic for an autism-specific evaluation., ${ }^{6,7}$ Yet research supports the idea that early intervention provided to children with ASD before 3 years of age is more effective than intervention provided after 5 years, ${ }^{8,9}$ and that intervention provided before 3 years of age may be even more effective. ${ }^{10}$ Most parents whose children will eventually be diagnosed with ASD first express concerns by the time the child is 18 months, with 30 to $40 \%$ of parents reporting concerns prior to the child's first birthday. ${ }^{11,12}$ Indeed, parents of children who exhibit early symptoms of ASD are often frustrated because their insights and concerns about their child's behaviors go unheeded by medical professionals. ${ }^{13}$ Given that some symptoms of ASD may emerge quite early, what are the barriers to identification of children at risk for ASD below the age of 3 ?

One of the reasons that ASD is hard to diagnose in very young children may be due to the criteria for Autistic Disorder listed in the Diagnostic and Statistical Manual-IV-TR. ${ }^{14}$
These criteria require that individuals display at least six features across three broad areas: (1) at least two symptoms of qualitative impairment in social interactions, including noted impairment in use of multiple nonverbal behaviors to regulate social interactions, failure to develop peer relations, lack of spontaneous seeking to show enjoyment or interests, or a lack of social-emotional reciprocity; (2) at least one symptom of a qualitative impairment in communication, that includes a delay (or lack of) spoken language without alternative communication compensation, noted impairment in conversational abilities, stereotyped and repetitive use of language, idiosyncratic language, or lack of varied spontaneous pretend or social play; and (3) at least one symptom showing a restricted range of interests and/or repetitive or stereotyped behaviors, including preoccupation that is abnormal in intensity or focus, inflexibility in routines, stereotyped or repetitive motor movements, or preoccupations with parts of objects. Given that many of these behaviors are age specific or development specific and are not typically seen in very young children (e.g., development of peer relationships, stereotyped interests, conversational skills), there is a great need for additional criteria to help practitioners and parents recognize signs of autism at younger ages.

In addition, to diagnose autism, it is also important to identify both the absence of behaviors that are usually exhibited by children with typical development and the presence of atypical behaviors. Thus, assessment measures that look only at the presence or absence of typical behaviors (as is common with many speech-language measures) will omit key information in the decision-making process. Further, repetitive behaviors are commonly seen in infants and toddlers who are developing typically. ${ }^{15-17}$ Therefore, distinguishing between what is typical and what is not typical can be difficult. Another reason that diagnosis has been hard to achieve at young ages is the lack of a definitive description of the developmental course of behaviors across domains in young children with autism.

Despite ambiguity in the nature of the early phenotype of autism, we do have evidence that identification of children with ASD is 
possible at 2 years of age. ${ }^{18,19}$ In two studies, the children showed social and communicative impairments at 2 years, although some of the children did not exhibit restrictive and repetitive behaviors until they were 3 years of age. Specific behaviors that discriminated children with autism from those without autism in the Manual for the Autism Diagnostic InterviewRevised $^{20}$ at age 2 years were: deficits in showing (directing attention); attention to voice; seeking to share own enjoyment; use of other's body as a tool; interest in other children; pointing; understanding gestures as well as hand/finger mannerisms; and unusual sensory behaviors ${ }^{\mathrm{Q} 3}{ }^{18}$ Stone and colleagues ${ }^{21}$ found that deficits in functional play, imitation, and directing attention were strong predictors of autism at age 2 years based on an observational instrument called the Screening Tool for $\mathrm{Au}^{-}$ tism in Two-Year-Olds (STAT). ${ }^{21}$ Attempts to identify children with autism at even younger ages $^{22-25 \mathrm{Q} 4}$ include the work of Baron-Cohen and his colleagues. These researchers developed the Checklist for Autism in Toddlers $\left(\mathrm{CHAT}^{\mathrm{Q} 5}\right)$ for health-care providers in England to screen for autism at 18 months of age. The CHAT includes nine parent-report "yesno" questions that assess various behaviors that could indicate autism (e.g., lack of pointing or pretend play) combined with five items that are observed by a home visitor. The CHAT had good specificity (98\%) in that most of the children identified as at risk in the screening later received a diagnosis of autism. However, the CHAT had poor sensitivity (38\%) in that several children were not identified as at risk in the screening and yet were subsequently diagnosed with autism. The absence of certain ageexpected behaviors (i.e., gaze monitoring, pointing to comment, social interest, attention to name, and pretend play) was key to early identification.

Efforts to improve the sensitivity of the CHAT using a parent questionnaire version entitled the Modified Checklist for Autism in Toddlers (M-CHAT) ${ }^{26}$ have shown progress. The M-CHAT relies entirely on parent report on the basis of 23 "yes-no" questions (e.g., Does your child enjoy being swung, bounced on your knee? Does your child understand what people say?). The goal of the M-CHAT was to broaden the CHAT's symptom checklist to identify a greater range of children with autism, to have the identification based entirely on parent report, and to shift the focal age group from 18 months to 24 months to improve psychometrics. However, the narrow response range (yes-no format), the relatively small number of questions, and the fact that field testing was conducted with older high-risk clinical samples represent limitations of the MCHAT. In addition, the targeted behaviors necessarily included the absence of higher-level social-communicative functions such as pointing to objects, pretend play, and imitation. Attempting to identify children at even younger ages, for example at 12 months of age, will be difficult due to the variability in the emergence of these skills in typically developing children and the fact that some children are just beginning to develop them around 12 months. Therefore, the results thus far suggest that these screening measures have limited validity below 18 months of age and very limited sensitivity to detect all children at risk for autism.

Despite these barriers, recent work across a variety of disciplines and behaviors has shown that there are differences in patterns of behavior below 2 years of age that distinguish children with autism from those who are typically developing as well as from those with other developmental disabilities. A variety of methodologies have been utilized to document the kinds of differences that may be seen in very young children with and without autism. Some of the earliest studies asked parents of children with autism to look back in a "retrospective" way and recall what their children were like at earlier ages. ${ }^{18,27-31}$ In hindsight most parents recall a variety of unusual features including lack of eye contact, limited vocalizations, lack of imitation, little interest in people, difficulty engaging in reciprocal games and interactions, poor response to shared focus of interest, dysregulated attention and affective expressions, behavioral difficulties, and sensory-motor and perceptual disturbances. Although these studies provided glimpses into early behaviors in these children, there were inherent drawbacks in this type of methodology. The accuracy with which family 
members could recall behaviors in the past (sometimes years earlier), and the fact that the information was gathered after the children had been diagnosed with ASD, may have biased the parents' views of what their children were like at younger ages. Due to these limitations, other methods have been used in an effort to confirm parental retrospective reports as well as to examine other aspects of early development that are not easily accessed via parent retrospective reports.

One such method for prospectively documenting early development in young children at risk for ASD is to monitor the growth and development of the younger siblings of children already diagnosed with ASD. ${ }^{32,33}$ Given that the incidence of ASD within families with another child with ASD is $\sim 9 \%,{ }^{34}$ observing the younger siblings for early signs of ASD has been productive. For example, Zwaigenbaum and colleagues ${ }^{32}$ tested infant siblings of children with ASD to identify specific aspects of behavior and temperament that can be measured at 6 and 12 months and that predict an eventual diagnosis of ASD. Yirmiya et $\mathrm{al}^{33}$ compared the infant siblings of children with autism to infant siblings of children with typical development at 4 and 14 months and found that most of the siblings of children with autism were doing as well as siblings of children with typical development. At the 14-month assessments, however, some group differences emerged in nonverbal requesting behaviors, as well as in language scores on the Bayley Scales, ${ }^{35}$ with differences largely attributable to delays among 6 of the 21 siblings of children with autism.

A third method for identifying characteristics of young children at risk for ASD is to conduct a prospective population study, where an entire community or population of children is screened from infancy on a set of specific behaviors. For example, Wetherby and colleagues $^{36}$ used the Infant-Toddler Checklist ${ }^{37}$ to screen large numbers of children in Tallahassee, FL, and successfully identified very young children who should be evaluated in greater depth for communication and other developmental disorders, including ASD. Further, Wetherby and coworkers ${ }^{36}$ identified a variety of behaviors that can be observed during assess- ment using the Communication and Symbolic Behavior Scales-Developmental Profile ${ }^{37}$ and can help discriminate toddlers with an ASD diagnosis from other toddlers who fail the Infant-Toddler Checklist. Charman and colleagues, ${ }^{38}$ Cox and coworkers, ${ }^{39}$ and Swettenham et $\mathrm{al}^{40}$ in Great Britain conducted several studies of developmental functioning among 20-month-olds with autism who initially were identified in CHAT screenings of the general population. These studies have also contributed to our insights regarding symptoms and development in toddlers with autism.

Another approach that has yielded information about symptoms that distinguish young children with autism from young children with other developmental problems has been the undertaking of studies that entail screening and/or more in-depth assessment of children who have already been identified due to developmental concerns. Studies representing this approach include that of Robins et $\mathrm{al}^{26}$ who have screened toddlers identified with developmental concerns using their instrument, the $\mathrm{M}$ CHAT, to investigate scoring criteria and key items that discriminate toddlers with autism from those with other developmental concerns. Lord and colleagues ${ }^{18,41}$ and Stone and associates $^{21,42}$ have conducted extensive research on the diagnosis of autism in 2-year-old children referred due to concerns about possible autism or other developmental problems.

Detailed descriptions of individual infants later diagnosed with autism have been provided in the literature via case studies. ${ }^{43-45}$ The case information regarding infant development is available for different reasons, such as extensive videotaping and/or diary notes made by a $\mathrm{pa}^{-}$ rent to document the infant's development, the participation of the infant in a research study investigating development during infancy prior to the identification of concerns related to autism (e.g., participating in a study of development of twins during infancy), or detailed assessment and intervention notes generated because of developmental concerns originating in early infancy.

A final method of identifying differences that might prove beneficial in diagnosing young children with or at risk for ASD is through the use of home videos made by parents before their 
children were diagnosed with ASD. ${ }^{15,46-50}$ One advantage of this type of retrospective video sampling is the naturalness of the setting for documenting behaviors as they typically occur in and around the child's home with familiar people, objects, and situations. Sampling may include a circumscribed situation such as the child's first birthday ${ }^{48}$ or a crosssection of everyday activities such as mealtime, bathtime, and playtime. ${ }^{46}$ One drawback to looking just at special occasions, however, is the limited sample of settings and behaviors displayed by the children during these special events. In addition, much of the previously cited work has focused primarily on socialcommunicative behaviors. ${ }^{47,49}$ Therefore, another reason for underidentification of young children with ASD could be that early infant development crosses domain-specific boundaries such that earlier manifestations of ASD do not fall solely within one developmental domain. Specifically, research using retrospective analysis of infant behavior has indicated the potential importance of examining both socialcommunicative symptoms and sensory features for early diagnosis.

Recent work by Baranek and her colleagues has attempted to bridge this gap by examining a range of sensory and social-communicative behaviors through retrospective video analysis. ${ }^{15,46,51,52,79 \mathrm{Q} 6}$ From home videos provided by parents, these researchers have selected an array of settings and situations that are naturally occurring in the child's life. Their work has shown that there are behaviors displayed by (or that are absent in) infants between the ages of 9 to 12 months, and even more so by 15 to 18 months, that can be used reliably to indicate those infants who were later diagnosed with ASD versus those who later developed typically or those with other types of developmental disorders.

Thus, the collective literature has highlighted a group of behaviors that can be used to help in the early identification of children with ASD. In an attempt to enhance the utility of the recent research in determining risk for ASD in clinical settings, this article ${ }^{\mathrm{Q} 7}$ focuses on characteristics in three primary areas: social communicative, sensory regulatory, and play. For each area, we first list behaviors that could indicate that a child is at risk for eventual diagnosis of ASD. Following each list, we present the developmental findings that argue for the importance of the behaviors in each area. We close with suggestions for clinicians to guide their work in early identification of infants and toddlers at risk for ASD and other disorders based on a pattern of social-communicative-sensory deficits.

\section{AT-RISK BEHAVIOR LISTS}

These lists were adapted from the work of Reznick and colleagues ${ }^{53}$ who reviewed the relevant literature to develop a tool to screen for behaviors suggesting social-communication-sensory deficits at 12 months of age (First Year Inventory, FYI). ${ }^{54}$ These lists were compiled from a large number of studies using the various methodologies described above. The references cited in the lists are not meant to be exhaustive, but rather point out examples of work indicating each behavior as a potential risk indicator.

\section{At-Risk Social-Communicative Behaviors}

- Failure to look up or orient toward a voice when the child's name is called ${ }^{15,32,48}$

- Difficulty hearing or discriminating among different speech sounds ${ }^{11,55,56}$

- Lack of use of intentional expressions, including gestures, to communicate desires, wants, or interests ${ }^{31,49,51}$

- Lack of babbling and delay in other aspects of language development ${ }^{32}$

- Lack of response to adult or child prompts or bids for social interaction ${ }^{18,43,57}$

- Lack of monitoring the gaze of adults, and failure to orient in the direction in which an adult is looking ${ }^{21,24,58}$

- Little orientation to faces ${ }^{59-61}$

- Averting gaze and failing to make eye contact $^{62-64}$

- Lack of coordination of gaze with other communicative behaviors ${ }^{36,43}$

- Tendency to withdraw from people and social interactions and to prefer being alone $e^{58,62,65}$ 
- Lack of social interest in others or engagement in reciprocal games ${ }^{28,32,66}$

- Relatively little emotional expression (e.g., social smiling), including facial, vocal, and gestural channels ${ }^{65,67}$

- Limited (or no) giving or showing of objects to another to share enjoyment ${ }^{48,63}$

- Little affective response to another's emo$\operatorname{tion}^{25,68}$

- Lack of imitative behaviors ${ }^{25,57,65}$

- Lack of initiating joint attention, or pointing at objects to direct the attention of another person ${ }^{18,48}$

- Regression, or loss of social-communicative skills or interest ${ }^{49,60,68}$

- Passive temperament or being undemanding of parental attention ${ }^{32,58}$

- Few vocalizations with consonants ${ }^{36}$

- Deficits in both behavior regulation and joint attention gestures, with presence of comparatively more social interaction gestures. $^{52}$

\section{Importance of Social-Communicative Behaviors}

Because social-communicative behaviors are at the heart of a diagnosis of ASD, it is important to gain a broad view of the child's use of and response to social-communicative bids. In typically developing infants, these behaviors appear early in life as signals of engagement such as sustained eye contact, vocalizations, and attention seeking or responsive motor movements. ${ }^{69-71}$ As children become more sophisticated, their communication and social exchanges include the use of gestures, eye gaze, and vocalizations (and later words) along with more coordinated use of these means to show their intentions to communicate. Gestures typically emerge at between 6 to 8 months of age and often include reaching to be picked up, pushing away objects, and open-handed reaching, followed by showing, giving, and pointing between 8 and 12 months. ${ }^{70,72,73}$

Between 8 and 9 months, typically developing infants begin to use eye gaze to direct others' attention, and the emergence of joint attentional abilities in the 9-month-old is a key landmark in communicative competence. ${ }^{69,74}$ Using eye gaze consistently to alter others' behavior is acquired over months and does not occur frequently until 12 months of age. ${ }^{69}$ Twelve-month-olds communicate primarily by using gestures and vocalizations; 18-montholds with a combination of gestures, vocalizations, and words or word approximations; and 24-month-olds communicate using primarily words or word combinations. ${ }^{75}$

Unlike typically developing children who naturally seek out social interaction, children with ASD have been reported to show limited responses to social stimuli as well as to exhibit few bids for social engagement. ${ }^{76}$ Some parents have reported retrospectively that their infants were not as attentive as their siblings at comparable ages or that it was more difficult to engage these infants in interaction. In using retrospective video analysis of home videos of 9- to 12-month-old children later diagnosed with ASD, Baranek ${ }^{15}$ was able to detect differences between these children and typically developing children as well as children with other developmental delays in social-communicative behaviors. For example, the children with ASD more frequently failed to respond to their own name and required more prompts during these social interactions. Likewise, Osterling and Dawson $^{48}$ found that not only was response to name impaired, but infants later diagnosed with ASD as compared with typically developing infants were also less likely to look at the faces of other people. Thus, infants who show limited interest in others or who appear difficult to engage in interactions with their caregivers are at risk for a broad range of communication deficits including ASD.

Not only do some children with ASD show less interest in social interactions, they also show deficits in their use of a variety of means to communicate. For example, parents retrospectively report less babbling and gesturing during early development in children with ASD compared with typically developing children. ${ }^{77}$ The early retrospective reports of these behaviors, however, did not discriminate children with ASD from children with mental retardation. ${ }^{58}$ Less gesturing was seen in both children with ASD and developmental disabilities at their first birthday parties ${ }^{49}$ and lack of appropriate gestures between 12 and 24 months was one characteristic 
distinguishing between children with ASD and with typical development. ${ }^{66}$

In looking for possible differences between groups, Watson and colleagues ${ }^{79}$ used retrospective video analysis to examine the use of communicative gestures in three groups of 9- to 12-month-old children (i.e., children with ASD, developmental disabilities, and typical development). Using a rating system that took into account both the quantity and diversity of gestures, the investigators found that the children with ASD and other developmental disabilities had lower gesture ratings than children with typical development; however, children in the autism group did not differ significantly from children with other developmental disabilities. In later studies, the number of subjects included in these analyses was expanded, and the researchers also examined changes in gesture use from 9 to 12 months to 15 to 18 months. ${ }^{51,52,79}$ The latter work has indicated that there is a widening gap in the use of gestures of all types between infants with autism and those developing typically from early to later infancy. This widening gap is attributable to a rapid expansion of gesture use among typically developing infants and a slow growth on average among infants with autism. The use of gestures by infants with other developmental disabilities generally falls between totals for the infants in the other two groups, but more detailed comparisons of the gesture use by infants with autism compared with infants with other developmental disabilities has been limited by a small number of infants with other developmental disabilities for whom longitudinal data are available at key time points.

In addition, some young children with ASD may show an overall deficit in early means of communication (e.g., eye gaze, early gestures such as showing, giving) and yet use means that typically develop later, such as taking someone's hand to lead them to an object or manipulating another's hand to open a door. For example, parents of 2-year-olds with ASD are less likely than parents of 2-year-olds with other developmental disabilities to report the coordination of gaze with other behaviors in requesting and more likely to report that their children use another person's hand as a tool. ${ }^{18}$ Although these "leading/manipulating" gestures are used communicatively, they are still viewed as presymbolic and may continue to be used long after the child should be using symbolic and conventional behaviors such as gestures and words. ${ }^{76}$ Thus, the typical means of communication used by the child, the variety of means of communication, and the developmental sequence of the means of communication are all important variables to consider in assessing young children who may be at risk for ASD, particularly for those children who are at the prelinguistic stage of development.

The ability to use a variety of communicative functions is another landmark area of weakness for young children with ASD. Commonly used categories for communicative functions are behavior regulation acts (.e.g, requests, protests), social interaction acts (e.g., social games, greetings, showing off), and joint attention acts (e.g., directing the attention of others to objects and events of interest) ${ }^{80}$ For typically developing children, behavior regulation acts and social interaction acts are typically seen before joint attention acts. ${ }^{70}$ Early behavior regulation acts appear as consistent vocalizations of displeasure, reaching to be picked up, pushing away undesired objects, or reaching for desired objects. Interspersed with the learning of behavior regulation acts are the social interaction acts used by the child to participate and eventually initiate social games. ${ }^{70}$ Between 8 and 12 months, the child is gaining rapid use of these functions followed soon by the emergence of early joint attention acts (e.g., showing, giving) and later joint attention acts (e.g, pointing). ${ }^{69,70}$ By age 12 months, a range of functions and acts should be exhibited and by 15 months, all three functions should be used consistently with a variety of means..$^{70,81}$

Numerous reports during the past 15 years of young children with ASD have noted the preponderance of communication for behavior regulation purposes, the limited number of acts related to social interaction, and few (or no) joint attention acts. ${ }^{82-84}$ In fact, this pattern of communicative functions discriminates with a high degree of reliability between children with ASD and children with other developmental disabilities. ${ }^{48,85}$ For example, in contrast to this pattern, children with Down syndrome show greater use of gestures related to social 
interaction and joint attention than behavior regulation. ${ }^{86}$

What might account for these differences across functions of communication and specifically for children with ASD? One issue that has received attention recently is the dyadic (i.e., child and other person) versus triadic (i.e., child, other person, and object/event) nature of these communicative acts. For example, both social interaction and behavior regulation acts may be used in dyadic interactions and later triadic interactions, whereas joint attention acts by definition can only occur in triadic interactions. ${ }^{87}$ Familiar social routines, imitative acts, and well-rehearsed formats associated with many social interactions may also involve less sophisticated behaviors than true joint focus. ${ }^{88}$ Further, even outside of social interactions, children with ASD have difficulty with shifting attention between stimuli. ${ }^{89}$ Thus, when these dyadic versus triadic and attentional characteristics are considered in conjunction with the social deficits inherent in ASD, difficulty in coordinating attention between a social partner and an object or event external to the dyad is predictable. ${ }^{87}$ In young children with ASD, communicating intentionally and for a variety of functions is difficult through nonverbal and verbal means. Indeed, distinct patterns of use of communicative functions have begun to emerge as characteristic of even very young children with ASD. ${ }^{90-92}$

In further analyses of the gestures used by infants with ASD and typical development at 9 to 12 and 15 to 18 months, Watson and colleagues $^{52}$ examined the three broad functions of behavior regulation, social interaction, and joint attention. Results indicated that at 9 to 12 months, although there were no significant differences between the groups on social interaction or joint attention (few joint attention behaviors noted in either group), there were significantly fewer behavior regulation gestures among children with ASD than among typically developing children. At the 15- to 18-month level, the largest difference between children with ASD and those with typical development was for joint attention gestures, although developmental trajectories also indicated increasing divergence between the two groups in social interaction gestures.
Interestingly, $40 \%$ of the children with ASD exhibited at least one joint attention gesture in a 10-minute sample of videotaped behavior at 15 to 18 months. This finding may help explain the poor sensitivity of the CHAT ${ }^{22,24}$ in identifying children with ASD at 18 months, due to its partial reliance on the absence of joint attention gestures in screening children for ASD at that age. In addition, the examination of gestures of infants with autism at 15 to 18 months revealed a very limited use of both joint attention and behavior regulation gestures, with a relative strength in the use of social interaction gestures such as routine baby games. Work by DiLavore and associates ${ }^{93}$ indicated their toddlers with ASD also showed a lag in using behavior regulation gestures when compared with children with developmental disabilities, although they eventually "caught up" to the children with development disabilities between 2 and 3 years of age.

In retrospective examination of the use of social interaction gestures in 9- to 12 -montholds, Colgan et $\mathrm{al}^{87}$ noted that $60 \%$ of the infants later diagnosed with ASD used no social interaction gestures, whereas only $29 \%$ of the typically developing infants failed to do so. The overall results indicated that it was not the quantity of social interaction gestures that differentiated between groups, but the diversity of gestures. For example, 5 of 8 infants with ASD who used any social interaction gestures used only one type of gesture (e.g., "peek-a-boo"), whereas 7 of 10 of the typically developing infants who used any gestures used more than one type of gesture.

With respect to social-communicative processes, young children with ASD also appear to be especially deficient in comprehension. The comprehension abilities of children with ASD, relative to nonverbal cognitive abilities, are significantly worse than their counterparts with specific language impairment or low intelligence. ${ }^{94}$ The lack of response of children with ASD to their own names at the age of 12 months has been previously discussed as one characteristic discriminating among children with ASD and children who are typically developing or developmentally delayed but without ASD. The auditory hyporesponsiveness of these children often leads their parents to have 
early concerns about the hearing abilities of their infants and toddlers. Parents of 2-yearolds with ASD are less likely to report that their children comprehend gestures than are parents of children with other developmental delays. ${ }^{18}$ Compounding their comprehension deficits, toddlers and preschoolers with ASD also have difficulty with nonverbal strategies that support the development of language comprehension. These strategies include monitoring the direction of others' gaze, as well as responding to explicit bids for joint attention as signaled by verbal cues (e.g., "Look!") and nonverbal cues (e.g., pointing and/or alternating gaze between the child and the object of interest)..$^{95-97}$ Baron-Cohen and colleagues ${ }^{98}$ demonstrated that these difficulties lead to mapping errors in vocabulary learning by young children with ASD, in contrast to children with other developmental disabilities. Thus, these deficits in important nonverbal strategies likely affect language comprehension in the immediate context as well as the acquisition of language over time.

Toddlers and preschoolers with ASD also have widespread difficulties with imitation. ${ }^{18,99}$ They show less spontaneous imitation and poorer skills in all aspects of elicited motor imitation. As in the area of attention and responsiveness to social and nonsocial stimuli, the reduced ability of children with ASD to imitate may restrict their ability to learn about the conventional uses of objects in the environment and conventional behavior of people as well as their ability to produce words and sentences.

One of the salient areas of deficit in preschool children with ASD is expressive language. Even during the later preschool years, these children demonstrate a substantial language delay compared with typically developing children. ${ }^{48,85}$ Indeed, it is often a delay in verbal communication that signals to parents and professionals that an evaluation is needed. Clearly, it is difficult to distinguish whether a child who is delayed in language production will have normal language by the preschool years, will go on to have a specific language impairment, or may have more significant disabilities such as ASD. However, by examining a range of behaviors within the child's understanding and use of language (and communi- cation) as well as other domains, professionals and parents can help make a differential diagnosis. For some young children with ASD, there may be evidence of oral-motor or phonological deficits. ${ }^{2,100}$ In addition, the previous issues related to limited social interactions, imitation, use and understanding of joint attention, and the symbolic limitations discussed below, all present challenges to the child with ASD in learning language. For the prelinguistic child, examining the child's comprehension, use of nonverbal communication means (e.g., eye gaze, gestures, vocalizations) and functions, as well as the child's social interaction, imitation, and play behaviors can provide valued information to help in decision making.

For young children with ASD who do talk, analyzing what language they use and how they use it are key elements, particularly when compared with early language competence of typically developing children. For the children who talk, their early language may be limited to the use of nouns and object names, with other types of words (e.g., action words, relational words, modifiers) appearing at a later time. ${ }^{101}$ In addition, some children may use echolalia and/or phrases or "chunks" of language from certain contexts and may import that content into unrelated, and possibly inappropriate, contexts. ${ }^{102,103}$ Questions related to whether children use their words for varied functions (e.g., behavior regulation, social interaction, joint attention), the appropriateness of the content, and the presence of echolalia may help in decision making for risk of ASD.

In summary, the available literature on the characteristics of young children with ASD indicates that there are patterns of development in social and communicative behaviors that are specific to ASD, several which can be detected as early as the end of the first year of life. In the following sections, we will review work related to other areas of deficit for these young children.

\section{At-Risk Sensory-Regulatory Behaviors}

- Abnormal pattern, focus, intensity, or duration of gaze g3,62,65 $^{4}$ 
- Difficulty visually disengaging from a target and/or shifting visual attention to a novel stimulus $^{15,32}$

- Hyper-responsiveness to sensory (visual, somatosensory, auditory, gustatory, or olfactory) stimuli ${ }^{15,65,68}$

- Hyporesponsiveness to sensory stimuli ${ }^{15,58,68}$

- Sensation-seeking behaviors or unusual sensory explorations of objects ${ }^{32,36,77}$

- Problems focusing eyes and/or attention on one target for appropriate periods of time ${ }^{15,66}$

- Difficulties in making transitions from one activity to another ${ }^{36}$

- Lack of regular cycles of wake/sleep/feeding or dysregulation of wake/sleep/feeding cycles ${ }^{28,43}$

- Abnormal muscle tone or posture, or clumsiness ${ }^{56,66,77}$

- Excessive irritability or tantrums, or difficulty calming when distressed ${ }^{36,65,104}$

- Intensely repetitive motor stereotypies, including hand flapping, finger mannerisms, body rocking, or other unusual motor actions ${ }^{37,49}$

- Excessive mouthing or licking of objects, toys, or hands ${ }^{15,43,58}$

\section{Importance of Sensory-Regulatory Behaviors}

Research using retrospective analysis of infant behaviors has indicated the potential importance of sensory features along with socialcommunicative symptoms for early diagnosis of ASD. ${ }^{15,58,62,65,66}$ Retrospective parent reports and laboratory experiments conducted with children with ASD during the first 2 years of life indicate several unusual responses to sensory stimuli and related self-regulatory difficulties. Hypo- and hyper-responsiveness to social (e.g., hugs, kisses) and nonsocial (e.g., noises, certain textures) stimuli have been reported in the literature as characteristic of some children with ASD. ${ }^{105,106}$ In the nonsocial domain, symptoms include both hyporesponsiveness, for instance to sounds ${ }^{28,56}$ or to pain, ${ }^{58}$ and hyper-responsiveness, as seen in aversion to the taste or texture of foods. ${ }^{58}$ Some unusual sensory features may be related to arousal modulation difficulties, resulting in disturbed sleep- wake cycles common among young children with ASD. ${ }^{28}$

The early work by Baranek, ${ }^{15}$ looking retrospectively at 9- to 12 -month-olds who were later diagnosed with ASD, demonstrated an ability to detect differences in sensory features between the children with ASD and those with typical development. The children with ASD oriented less to novel visual stimuli, mouthed objects excessively, and showed aversions to social touch. Baranek ${ }^{107}$ has also argued, however, that sensory sensitivities are not seen in all children with ASD, and other reports indicate that other disability groups may also manifest sensory deficits (e.g, children with fragile $\mathrm{X}$ syndrome). In addition, some children may show mixed patterns of hypo- and hyper-responsiveness. ${ }^{68}$

Research on young children with ASD suggests that these differences in sensory processing are magnified with social stimuli. For example, Dawson and colleagues ${ }^{108}$ studied orienting responses to both social and nonsocial stimuli in young children with ASD as compared with a group with developmental delays and found that the children with ASD were less likely to orient to all stimuli, but this pattern was more extreme for the social stimuli. Swettenham and colleagues ${ }^{40}$ demonstrated that 20-month-old toddlers with ASD had deficits in social orienting relative to children with typical development and those with developmental delays. Similarly, retrospective video analyses have yielded deficits in social and nonsocial orienting in infants by 12 months of age. $^{15,48 \mathrm{Q} 8}$ These early differences in responsiveness to stimuli may preclude the child's normal explorations of his/her environment, the acquisition of increasingly conventional knowledge of both the nonsocial and social world, and the meaningfulness of subsequent interactions with people and objects. In addition, they may be precursors to symptoms such as increased attention to parts of objects and repetitive behaviors seen in older children.

Another area of sensory sensitivity with particular interest to speech-language pathologists is feeding. Issues with the type, texture, and presentation of food (e.g., location on the plate, food groups not touching) have been seen in children with ASD. ${ }^{109}$ Older school-age 
children with ASD have more feeding difficulties than typically developing peers, but little information is available on very young children with ASD. Thus, sensory processing difficulties for some children may be an important part of both the assessment and the intervention plans to facilitate communication and feeding skills and to promote the ability to regulate the environment. Further, the overall pattern of unusual behaviors in both the social-communicative and sensory processing categories is more indicative of ASD than any one particular symptom at this early age. Major questions still unanswered include the degree to which these sensitivities challenge the child with ASD and his/her caregivers, and whether they in fact compound the child's difficulties engaging with others in social interactions. These types of sensory features have been hypothesized to help explain the difficulties some young children with ASD have in new or transitioning situations. In addition, without adequate communication skills to describe these sensitivities, children with ASD may have no other means to demonstrate their discomfort except in counterproductive ways (e.g., screaming, having tantrums).

In summary, the literature on the characteristics of young children with ASD indicates that there are patterns of development in sensory processing and regulatory functions that are specific to ASD and that can be detected as early as the end of the first year of life. Close examination of sensory processing and regulatory functioning is critical when assessing children for possible risk factors associated with ASD.

Q31 At-Risk Play Behaviors ${ }^{031}$

A number of studies offer examples of at-risk play behavior that might indicate a child at risk for ASD. ${ }^{15,25,28,29,32,36,46,65}$

- Unusual play such as preference for parts of objects

- Attachments to odd objects

- Extensive solitary play

- Lack of pretend play

- Lack of play with varied toys

- Repetitive play with objects.

\section{Importance of Play Behaviors}

Observing a child in play can provide information about a child's social, cognitive, communicative, physical, and symbolic skills. A child's play reflects both internal characteristics of the child and the opportunities and influences that surround the child. Through play, children gain an understanding of the objects and people in their environment. Observing the child's play can be an important means for gaining information about what the child knows. Object play in typically developing children shows a clear developmental pattern, and the type and variety of play can be predictive of overall developmental level as well as future skills in some domains. Although there is no one commonly accepted scale to measure object play in very young children, there is agreement as to a progression of developmental levels of play with four general categories of play (i.e., exploratory, relational, functional, and symbolic). ${ }^{46,111,112}$ Some play schemas further break down the categories into subcategories, such as children using first ${ }^{\mathrm{Q} 9}$ indiscriminate actions on objects, then later simple manipulations on objects as components of exploratory play.

Exploratory play in children in the first 4 months of life involves looking at, holding, and mouthing objects. By 4 to 8 months, as fine motor skills increase, play expands to also include banging, shaking, and manipulating objects. In these early months, there is no apparent functional relationship between the infant's actions and the actual object; for example, the infant may explore all objects in the same ways by mouthing them or applying simple repetitive manipulations such as banging, shaking, and poking. By 8 to 12 months, infants begin to manipulate objects more readily, throwing and dropping them, giving and showing them to adults, and they begin to be participants in social games (e.g., patty-cake). By 12 to 18 months, toddlers typically push, pull, turn on, put in, and take out objects. They are beginning to stack objects and figure out the relationships between play objects. The advent of relational play indicates growth in the child's play skills. In addition, as children are looking at others and what others do with objects, they begin to recognize common and socially defined uses of objects. Thus, functional play with 
objects such as "combing hair with a comb" or "putting a toy cup to mouth" is beginning to appear in children at this age.

Between 18 and 24 months, toddlers are playing easily with a variety of toys (e.g., blocks, cars, dolls, sandbox toys, stuffed animals) and should be clearly showing their knowledge of how to use these toys in functional and pretend ways (e.g., feeding a doll). In addition, symbolic play actions begin to be exhibited such as pretending inanimate objects are real (e.g., a doll walks, dinosaurs eat things), substituting objects for one another (e.g., a block represents food), or using imaginary objects (e.g., combing hair without a comb). By 24 to 36 months, more elaborate actions on objects should be displayed such as figuring out how to open containers with screw lids, winding up simple toys, fitting simple shapes into their associated holes, and using more elaborated pretend play.

For most children, play and communication skills are highly correlated during certain stages of development and both reflect common underlying cognitive processes. ${ }^{113,114}$ For example, early instances of what is often called "pretend play" often co-occur with the onset of words along with more consistent communicative gestures. ${ }^{115}$ Therefore the emergence of this type of play may also indicate a cognitive readiness for consistent gesture use and word approximations or words (depending on the other skills the child has available). Further, as children begin to combine words (20 to 24 months), single pretend schemes are typically joined together (e.g., child stirs and then feeds self). ${ }^{116} \mathrm{~A}$ child who is combining play behaviors but not words may be showing symbolic readiness for word combinations. By 28 months, most children are producing longer sentences, sequencing their play actions, and play-acting familiar scenarios. Three-year-olds are developing their ability to play actively with others, although for short periods of time, and are improving their ability to take turns.

The level of both functional and symbolic play exhibited by young children is also predictive of later language skills. ${ }^{116,117}$ Lyytinen and colleagues observed that symbolic play skills at 14 months of age were predictive of receptive and expressive language at both 24 and 42 months. There is also evidence that play level can help predict outcome of intervention. ${ }^{118}$ Yoder et a ${ }^{118}$ documented that prelinguistic children with developmental disabilities who demonstrated symbolic play behaviors were more likely to increase their rate of communication during an intervention program.

The object play of children with ASD shows clear differences when compared with the play of typically developing children. Children with ASD have been reported to exhibit limited functional and symbolic play with objects; exhibit atypical play preferences; lack creativity, variety, or flexibility in their play; and show preoccupation with certain features of toys. ${ }^{92,119,120}$ In addition, they also have a limited capacity for imitation ${ }^{121}$ and exhibit fewer novel pretend play acts. ${ }^{122}$ Further, limitations in higher-level symbolic play are more apparent in structured versus unstructured situations. ${ }^{121,123}$ In comparison with children with typical development or with mental retardation, children with ASD use less appropriate, less varied, and more repetitive play ${ }^{122}$ and persist in lower-level sensorimotor play. ${ }^{124} \mathrm{Be}-$ cause pretend play reflects a child's ability to watch and imitate actions of other people in his or her environment, the deficits in social responsiveness and imitation of children with ASD may be among the factors contributing to their limited play repertoire.

Most of the play studies have involved preschool children with ASD, and few studies have looked closely at play in infants and toddlers with ASD. The few studies that have looked at very young children later diagnosed with ASD indicate little difference in early levels of exploratory play between typically developing children and those with ASD or developmental delays. For example, Baranek and colleagues ${ }^{46}$ noted that at 9 to 12 months, all three groups demonstrated similar amounts of time in play and most children in each group exhibited indiscriminate actions and simple manipulations of objects. Therefore, amount of play at the exploratory level did not significantly discriminate between the groups. However, only 1 out of 10 of the children with developmental delays showed any play behaviors above exploratory (i.e., relational or above), 2 of the 11 children with ASD exhibited some low level relational play, but 2 of the 
11 typically developing children displayed functional play. Thus, patterns were beginning to emerge in higher level play (relational and functional) at the 9- to 12-month level. Further, Watson et a ${ }^{79}$ demonstrated that achievement of relational play at 9 to 12 months was predictive of whether and how long children performed relational play acts at 15 to 18 months. Several studies ${ }^{121,123}$ have also demonstrated that young children with ASD may be capable of higher-level play skills under structured situations. For example, when prompted with objects or gestural cues, they are more likely to exhibit skills that are in their repertoires, but that are not initiated independently. Thus, assessment aimed at early identification should look at the child's level of play as well as include dynamic or scaffolded components whereby practitioners can probe to see whether a child's play level may be enhanced with structure and support.

Children are at risk for communication and other developmental deficits when they: primarily display play behaviors representative of younger children; have limited play behaviors (e.g., play with only one type of toy, play very briefly with toys); seem averse to playing with others (including caregivers); play alone for longer periods of time than would be expected at their developmental age (e.g., 1 hour for an 18-month-old); have stereotypic play behaviors (e.g., continuously spin the wheels of a car, rigidly line up their toys); or display unusual play behaviors (e.g., rub toys across their face or hands, lick and smell toys). Children who are between 12 and 18 months who are not showing signs of functional or pretend play or who are 18 to 24 months old and are not exhibiting any symbolic play behaviors may be at risk for communication deficits. Observation and caregiver report of a child's play behaviors can provide a baseline for the child's overall developmental level, and more specifically, reveal the child's potential for the development or refinement of associated communication skills.

\section{SUMMARY AND RECOMMENDATIONS}

In summary, there is now evidence across a range of behavioral domains that supports the contention that children with ASD may be identified at earlier ages than previously demonstrated. As indicated by the brief literature provided, the key to early assessment is to gather the appropriate data. Specifically, practitioners must attend to a wide array of domains and observe, evoke, and ask parents about behaviors that have not been a part of traditional assessment (or even screening) batteries. In addition, early intervention service providers and health, medical, education, and early care providers all need to be a part of the "village" that helps in the early identification process.

Referrals of infants into the Part C early intervention system ${ }^{\mathrm{Q} 10}$ are often based on the existence of medical conditions or risks identified by the primary health provider, whereas children who enter the system due to developmental delays are more likely to enter as toddlers after 21 months of age. ${ }^{125}$ Given the rather late identification of children with ASD and the growing literature to indicate that it is possible to identify these children at younger ages, all of those who interact with young children could be potential referral sources. Indeed, in some states, childcare providers are the fastest growing source of referrals for children suspected of developmental disabilities to the early intervention system. ${ }^{126}$ In addition, the potential role of physicians in first-level screenings for developmental delays or disorders is especially important. In the case of ASD, initial parental concerns leading to an eventual diagnosis of ASD are often first raised with a child's primary health-care provider. Thus, it is important for the early intervention service providers to keep physicians and childcare providers up to date about early symptoms of ASD and to offer a screening process with applicability to physicians' offices as well as to childcare centers and specialized developmental evaluation settings to which infants and toddlers may be referred. The American Academy of Pediatrics currently emphasizes the importance of developmental surveillance, a process involving probes for age-appropriate developmental skills at each well-child visit, as well as of asking about parent concerns. ${ }^{127}$

In addition, practitioners who provide specialized services to children with developmental 
disabilities must modify their assessment and intervention practices to incorporate the recent research and findings related to early identification of children with ASD. As new tools for assessment and screening of young children with ASD are developed, researchers and practitioners should work closely with family members to ensure the most effective and child- and family-friendly assessment practices. As research informs practice, so should practice inform research. Collaborative partnerships of researchers, practitioners, and consumers, as encouraged by many national organizations, can be a positive step toward enhanced service delivery.

\section{REFERENCES}

1. Centers for Disease Control and Prevention. Mental health in the United States: parental report of diagnosed autism in children aged 417 years-United States, 2003-2004. MMWR Morb Mortal Wkly Rep 2006;55:481-486

2. National Research Council. Educating Children with Autism. Washington, DC: National Academy Press; 2001

3. Individuals with Disabilities Education Improvement Act of 2004, 34 CFR $\$ 300.7$ (2004)

4. Gernsbacher M, Dawson M, Goldsmith H. Three reasons to believe in an autism epidemic. Current Direc Psych Sci 2004;32:373-396 ${ }^{\text {Q11 }}$

5. Chakrabarti S, Fombonne E. Pervasive developmental disorders in preschool children. JAMA 2001;285:3093-3099

6. Filipek PA, Accardo PJ, Baranek GT, et al. The screening and diagnosis of autistic spectrum disorders. J Autism Dev Disord 1999;29:439-484

7. Mandell D, Novak M, Zubritsky C. Factors associated with age of diagnosis among children with autism spectrum disorders. Pediatrics 2005; 116:1480-1486

8. Fenske E, Zalenski S, Krantz P, McClannahan L. Age at intervention and treatment outcome for autistic children in a comprehensive intervention program. Analysis Intervent Dev Disabil 1985;5: 49-58 Q12

9. Harris S, Handleman J. Age and IQ at intake as predictors of placement for young children with autism: a four- to six-year follow-up. J Autism Dev Disord 2000;30:137-142

10. McGee G, Morrier M, Daly T. An incidental teaching approach to early intervention for toddlers with autism. J Assoc Pers Sev Handicaps 1999;24:133-146
11. De Giacomo A, Fombonne E. Parental recognition of developmental abnormalities in autism. Eur Child Adolesc Psychiatry 1998;7:131-136

12. Siegel B, Pliner C, Eschler J, Elliott GR. How children with autism are diagnosed: difficulties in the identification of children with multiple developmental delays. J Dev Behav Pediatr 1988;9: 199-204

13. Schall C. Family perspectives on raising a child with autism. J Child Fam Stud 2000;9:409-423

14. American Psychiatric Association. Diagnostic and Statistical Manual of Mental Disorders. 4th ed. Washington, DC: American Psychiatric Association; 2000

15. Baranek G. Autism during infancy: a retrospective video analysis of sensory-motor and social behaviors at 9-12 months of age. J Autism Dev Disord 1999;29:213-224

16. Symons F, Sperry L, Dropik P, Bodfish J. The early development of stereotypy and self-injury: a review of research methods. J Intellect Disabil Res 2005;49:144-158

17. Thelen E. Rhythmical behavior in infancy: an ethological perspective. Dev Psychol 1981;17: 237-257

18. Lord C. Follow-up of two-year-olds referred for possible autism. J Child Psychol Psychiatry 1995; 36:1365-1382

19. Stone WL, Lee EB, Ashford L, et al. Can autism be diagnosed accurately in children under three years? J Child Psychol Psychiatry 1999;40:219226

20. Rutter M, LeCouteur A, Lord C. Manual for the Autism Diagnostic Interview. Rev, ed. Los Angeles, CA: Western Psychological Services; 2003

21. Stone W, Coonrod E, Ousley O. Brief report: screening tool for autism in two-year-olds (STAT): development and preliminary data. J Autism Dev Disord 2000;30:607-612

22. Baird G, Charman T, Baron-Cohen S, et al. A screening instrument for autism at 18 months of age: a 6-year follow-up study. J Am Acad Child Adolesc Psychiatry 2000;39:694-702

23. Baron-Cohen S, Allen J, Gillberg C. Can autism be detected at 18 months? The needle, the haystack, and the CHAT. Br J Psychiatry 1992;161:839843

24. Baron-Cohen S, Cox A, Baird G, et al. Psychological markers in the detection of autism in infancy in a large population. Br J Psychiatry 1996; 168:158-163

25. Charman T, Swettenham B, Cox A, Baird G, Drew A. An experimental investigation of socialcognitive abilities in infants with autism: clinical implications. Infant Ment Health J 1998;19:260 275 
26. Robins D, Fein D, Barton M, Greene J. The Modified Checklist for Autism in Toddlers: an initial study investigating the early detection of autism and pervasive developmental disorders. J Autism Dev Disord 2001;31:131-144

27. Wing L. The handicaps of autistic children-a comparative study. J Child Psychol Psychiatry 1969;10:1-40

28. Dahlgren SO, Gillberg C. Symptoms in the first two years of life. Euro Arch Psychiatry Neurol Sci 1989;238:169-174

29. Stone W, Lemanek K. Parental report of social behaviors in autistic preschoolers. J Autism Dev Disord 1990;20:513-522

30. Vostanis P, Smith B, Corbett J, et al. Parental concerns of early development in children with autism and related disorders. Autism 1998;2:229242

31. Wimpory DC, Hobson RP, Williams JMG, Nash S. Are infants with autism socially engaged? A study of recent retrospective parental reports. J Autism Dev Disord 2000;30:525-536

32. Zwaigenbaum L, Bryson S, Rogers T, Roberts W, Brian J, Szatmari P. Behavioral manifestations of autism in the first year of life. Int J Dev Neurosci 2005;23:143-152

33. Yirmiya N, Gamliel I, Pilowsky T, Feldman R, Baron-Cohen S, Sigman M. The development of siblings of children with autism at 4 and 14 months: social engagement, communication, and cognition. J Child Psychol Psychiatry 2006; 47:511-523

34. Szatmari P, Jones M, Zwaigenbaum L, MacLean J. Genetics of autism: overview and new directions. J Autism Dev Disord 1998;28:351-368

35. Bayley N. Bayley Scales of Infant Mental Development-Revised. 2nd ed. New York, NY: Psychological Corp; 1993

36. Wetherby A, Woods J, Allen L, Cleary J, Dickinson H, Lord C. Early indicators of autism spectrum disorders in the second year of life. J Autism Dev Disord 2004;34:473-493

37. Wetherby A, Prizant B. Communication and Symbolic Behavior Scales-Developmental Profile (CSBS-DP). First Normed Edition. Baltimore, MD: Paul H Brookes; 2002

38. Charman T, Baron-Cohen S, Swettenham J, Baird G, Drew A, Cox A. Predicting language outcome in infants with autism and pervasive developmental disorder. Int Lang Commun Disord 2003;38:265-285

39. Cox A, Klein K, Charman T, et al. Autism spectrum disorders at 20 and 42 months of age: stability of clinical and ADI-R diagnosis. J Child Psychol Psychiatry 1999;40:719-732

40. Swettenham J, Baron-Cohen S, Charman T, et al. The frequency and distribution of spontaneous attention shifts between social and nonsocial stimuli in autistic, typically developing, and nonautistic developmentally delayed infants. J Child Psychol Psychiatry 1998;39:747-753

41. Lord C, Shulman C, DiLavore P. Regression and word loss in autistic spectrum disorders. J Child Psychol Psychiatry 2004;45:936-955

42. Stone W, Coonrod E, Turner L, Pozdol S. Psychometric properties of the STAT for early autism screening. J Autism Dev Disord 2004;34: 691-701

43. Dawson G, Osterling J, Meltzoff A, Kuhl P. Case study of the development of an infant with autism from birth to two years of age. J Appl Dev Psychol 2000;21:299-313

44. Rutherford M. A retrospective journal-based case study of an infant with autism and his twin. Neurocase 2005;11:129-137

45. Sparling J. Brief report: a prospective case report of infantile autism from pregnancy to four years. J Autism Dev Disord 1991;21:229-236

46. Baranek G, Barnett C, Adams E, Wolcott N, Watson L, Crais E. Object play in infants with autism: methodological issues in retrospective video analysis. Am J Occup Ther 2005;59:2030

47. Eriksson AS, de Chateau P. Brief report: a girl aged two years and seven months with autistic disorder videotaped from birth. J Autism Dev Disord 1992;22:127-129

48. Osterling J, Dawson G. Early recognition of children with autism: a study of first birthday home videotapes. J Autism Dev Disord 1994;24: 247-257

49. Osterling JA, Dawson G, Munson JA. Early recognition of 1-year-old infants with autism spectrum disorder versus mental retardation. Dev Psychopathol 2002;14:239-251

50. Maestro S, Muratori F, Cristina Cavallaro M, et al. How young children treat objects and people: an empirical study of the first year of life in autism. Child Psychiatry Hum Dev 2005;35: 383-396

51. Neitzel J, Watson L, Baranek G, Crais E, Dysinger A, Wood, Barry S. Gesture use in infants with autism at 9-12 and 15-18 months. Presented at: The Biennial Meeting of the Society for Research and Child Development; April 2427, 2003; Tampa, FL ${ }^{\mathrm{Q} 13}$

52. Watson L, Baranek G, Crais E. Gesture development in infants with autism spectrum disorders. Presented at: Gatlinburg Conference on Theory and Research in Intellectual and Developmental Disabilities; March 2005; Annapolis, MD

53. Gillberg C, Nordin V, Ehlers S. Early detection of autism: diagnostic instruments for clinicians. Eur Child Adolesc Psychiatry 1996;5:67-74

54. Ohta M, Nagai Y, Hara H, et al. Parental perception of behavioral symptoms in Japanese 
autistic children. J Autism Dev Disord 1987;17: 549-563

55. Kurita H. Infantile autism with speech loss before the age of thirty months. J Am Acad Child Psychiatry 1985;24:191-196

56. Hoshino Y, Kumashiro H, Yashima Y, Tachibana R, Watanabe M, Furukawa H. Early symptoms of autistic children and its diagnostic significance. Folia Psychiatr Neurol Jpn 1982;36:367-374

57. Bernabei P, Camaioni L, Levi G. An evaluation of early development in children with autism and pervasive developmental disorders from home movies: preliminary findings. Autism 1998;2: 243-258

58. Maestro S, Casella C, Milone A, et al. Study of the onset of autism through home movies. Psychopathology 1999;32:292-300

59. Zakian A, Malvy J, Desombre H, et al. Early signs of autism and family films: a new study by informed evaluators and those unaware of the diagnosis. Encephale 2000;26:38-44

60. Adrien JL, Perrot A, Sauvage D, et al. Early symptoms in autism from family home movies: evaluation and comparison between 1 st and 2 nd year of life using I.B.S.E. scale. Acta Paedopsychiatr 1992;55:71-75

61. Mars A, Mauk J, Dowrick P. Symptoms of pervasive developmental disorders as observed in prediagnostic home videos of infants and toddlers. J Pediatr 1998;132:500-504

62. Rogers S, DiLalla D. Age of symptom onset in young children with pervasive developmental disorders. J Am Acad Child Adolesc Psychiatry 1990;29:863-872

63. Gillberg C, Ehlers S, Schaumann H, et al. Autism under age 3 years: a clinical study of 28 cases referred for autistic symptoms in infancy. J Child Psychol Psychiatry 1990;21:921-934

64. Adrien J, Martineau J, Perrot A, Hameury L, Larmande C, Sauvage D. Blind ratings of early symptoms of autism based upon family home movies. J Am Acad Child Adolesc Psychiatry 1993;32:617-626

65. Adrien J, Ornitz E, Barthelemy C, Savage D, Lelord G. The presence or absence of certain behaviors associated with infantile autism in severely retarded autistic and nonautistic retarded children and very young normal children. J Autism Dev Disord 1987;17:407-416

66. Greenspan S, Wieder S. Developmental patterns and outcomes in infants and children with disorders in relating and communicating: a chart review of 200 cases of children with autistic spectrum diagnoses. J Dev Learn Disord 1997;1: 87-141 Q14

67. Carpenter M, Nagell K, Tomasello M. Social cognition, joint attention, and communicative competence from 9 to 15 months of age. Monogr Soc Res Child Dev 1992;255:63 Q15

68. Crais E, Douglas D, Campbell C. The intersection of the development of gestures and intentionality. J Speech Lang Hear Res 2004;47:678694

69. Jones SE, Zimmerman DH. A child's point and the achievement of intentionality. Gesture 2003;3: $155-185^{\mathrm{Q} 16}$

70. Carpenter R, Mastergeorge A, Coggins T. The acquisition of communicative intentions in infants eight to fifteen months of age. Lang Speech 1983;26:101-116

71. Thal D, Tobias S. Communicative gestures in children with delayed onset of oral expressive vocabulary. J Speech Hear Res 1992;35:12811289

72. Saxon T, Frick J, Colombo J. A longitudinal study of maternal interactional styles and infant visual attention. Merrill Palmer Q 1997;43:48-66

73. Wetherby A, Cain D, Yonclas D, Walker V. Analysis of intentional communication of normal children from the prelinguistic to the multiword stage. J Speech Hear Res 1988;31:240-252

74. Wetherby A, Prizant B, Hutchinson T. Communicative, social/affective, and symbolic profiles of young children with autism and pervasive developmental disorders. Am J Speech Lang Pathol 1998;7:79-91

75. Ornitz EM, Guthrie D, Farley AH. The early development of autistic children. J Autism Dev Disord 1977;7:207-229

76. Baranek G, Watson L, Crais E, Alcott K. Video analysis of gesture in infants with autism at 9-12 months. SRCD; 2001 ${ }^{\mathrm{Q} 17}$

77. Watson L, Crais E, Baranek G, Roy V, Dykstra J. Longitudinal relations between play and gestures in infants with autism. Presented at: The American Speech-Language-Hearing Association Convention; 2004; Philadelphia, PA

78. Bruner J. The social context of language acquisition. Lang Commun 1981;1:155-178

79. Coggins T, Mastergeorge A, Carpenter R. The acquisition of communicative intentions in infants eight to fifteen months of age. Lang Speech 1983; 26:101-116

80. McEvoy R, Rogers S, Pennington R. Executive function and social communication deficits in young autistic children. J Child Psychol Psychiatry 1993;34:563-578

81. Mundy P, Crowson M. Joint attention and early social communication: implications for research on intervention with autism. J Autism Dev Disord 1997;27:653-675

82. Mundy P, Sigman M, Kasari C. Joint attention, developmental level, and symptom presentation in autism. Dev Psychol 1994;6:389-401 
83. Mundy P. Joint attention and social-emotional approach behavior in children with autism. Dev Psychopathol 1995;7:63-82 ${ }^{\mathrm{Q} 18}$

84. Mundy P, Kasari C, Sigman M, Ruskin E. Nonverbal communication and early language acquisition in children with Down syndrome and in normally developing children. J Speech Hear Res 1995;38:157-167

85. Colgan S, Lanter L, McComish C, Watson L, Crais E, Baranek G. Analysis of social interaction gestures in infants with autismJ Child Neuropsychol 2006. In press ${ }^{\mathrm{Q} 19}$

86. Rollins PR, Wambacq I, Dowell D, Mathews L, Reese PB. An intervention technique for children with autistic spectrum disorder: joint attentional routines. J Commun Disord 1998;31:181-193

87. Landry R, Bryson SE. Impaired disengagement of attention in young children with autism. J Child Psychol Psychiatry 2004;45:1115-1122

88. Attwood A, Frith U, Hermelin B. The understanding and use of interpersonal gestures by autistic and Down's syndrome children. J Autism Dev Disord 1988;18:241-257

89. Carpenter M, Pennington B, Rogers S. Interrelations among social-cognitive skills in young children. J Autism Dev Disord 2001;32:91-106

90. Wetherby A, Prutting C. Profiles of communicative and cognitive-social abilities in autistic children. J Speech Hear Res 1984;27:364-377

91. DiLavore PC, Lord C, Rutter M. The prelinguistic autism diagnostic observation schedule. J Aut Dev Disord 1995;25:355-379

92. Fein D, Dunn M, Allen D, et al. Language and neuropsychological finding. In: Rapin L, ed. Preschool Children with Inadequate Communication. London, UK: Mac Keith; 1996:123-154

93. Leekam S, Baron-Cohen S, Perrett D, Milders M, Brown S. Eye-direction detection: a dissociation between geometric and joint attention skills in autism. Br J Dev Psychol 1997;15(Pt 1):77$95^{\mathrm{Q} 20}$

94. Leekam S, Hunnisett E, Moore C. Targets and cues: gaze-following in children with autism. J Child Psychol Psychiatry 1998;39:951-962

95. Sigman M, Kasari C. Joint attention across contexts in normal and autistic children. In: Moore C, Dunham PJ, eds. Joint Attention: Its Origins and Role in Development. Hillsdale, NJ: Lawrence Erlbaum; 1995:189-203

96. Baron-Cohen S, Baldwin DA, Crowson M. Do children with autism use the speaker's direction of gaze strategy to crack the code of language? Child Dev 1997;68:48-57

97. Stone W, Ousley O, Littleford C. A comparison of elicited imitation in young children with autism and developmental delay. Presented at: The Gatlinburg Conference on Research and Theory of Mental Retardation; 1995; Gatlinburg, TN
98. Lord C, Paul R. Language and communication in autism. In: Cohen DJ, Volkmar FR, eds. Handbook of Autism and Pervasive Developmental Disorders. 2nd ed. New York, NY: Wiley; 1997: 195-225

99. Carpenter M, Tomasello M. Joint attention, cultural learning, and language acquisition. In: Wetherby AM, Prizant BM, eds. Autism Spectrum Disorders: A Transactional, Developmental Perspective. Baltimore, MD: Brookes; 2000:3154

100. Prizant B, Schuler A, Wetherby AM, Rydell PJ. Enhancing language and communication: language approaches. In: Cohen DJ, Volkmar FR, eds. Handbook of Autism and Pervasive Developmental Disorders. 2nd ed. New York, NY: Wiley; 1997:572-605

101. Tsatsanis K. Heterogeneity in learning style in Asperger syndrome and high functioning autism. Topics Lang Disord 2004;24:260$270^{\mathrm{Q} 21}$

102. Hoshino Y, Kaneko M, Yashima Y, Jumashiro H, Volkmar FR, Cohen DJ. Clinical features of autistic children with setback course in their infancy. Jpn J Psychiatry Neurol 1987;41:237245

103. Kientz MA, Dunn W. A comparison of the performance of children with and without autism on the Sensory Profile. Am J Occup Ther 1997; 51:530-537

104. Anzalone M, Williamson G. Sensory processing and motor performance in autism spectrum disorders. In: Wetherby AM, Prizant BM, eds. Autism Spectrum Disorders: A Transactional Developmental Perspective. Baltimore, MD: Paul Brookes; 2000:143-166

105. Baranek G. Efficacy of sensory and motor interventions for children with autism. J Autism Dev Disord 2002;5:397-422

106. Dawson G, Meltzoff AN, Osterling J, Rinaldi J, Brown E. Children with autism fail to orient to naturally occurring social stimuli. J Autism Dev Disord 1998;28:479-485

107. Ahearn WH, Castine T, Nault K, Green G. An assessment of food acceptance in children with autism or pervasive developmental disorder- not otherwise specified. J Autism Dev Disord 2001; 31:505-511

108. Schreck K, Williams K, Smith A. A comparison of eating behaviors between children with and without autism. J Autism Dev Disord 2004;34: 433-438 22

109. Belsky J, Most R. From exploration to play: a cross-sectional study of infant free play behavior. 1981; ${ }^{\mathrm{Q} 23}$ 17:630-639

110. Casby M. Symbolic play: development and assessment considerations. Infants Young Child $1992 ; 4: 43-48$ 
111. Bates E, Bretherton I, Snyder L, Shore C, Volterra V. Vocal and gestural symbols at 13 months. Merrill Palmer Q1980;2:407-423

112. Thal D. Language and cognition in normal and late-talking toddlers. Topics Lang Disord 1991; $11: 33-42^{\mathrm{Q} 24}$

113. Kennedy M, Sheridan M, Radlinski S, Beeghly M. Play-language relationships in young children with developmental delays: implications for assessment. J Speech Hear Res 1991;34:112-122

114. Lyytinen P, Laakso M, Poikkeus A, Rita N. The development and predictive relations of play and language across the second year. Scand J Psychol 1999;40:177-186

115. Lyytinen P, Poikkeus A, Laakso M, Eklund K, Lyytinen H. Language development and symbolic play in children with and without familial risk of dyslexia. J Speech Lang Hear Res 2001;44:873885

116. Yoder P, et al. Predicting children's response to two prelinguistic communication interventions. J Early Intervention 1995;19:74-84 25Q26

117. Jarrod C, Boucher J, Smith P. Executive function deficits and the pretend play of children with autism: a research note. J Child Psychol Psychiatry 1994;35:1473-1482

118. Ferrara L, Hill S. The responsiveness of autistic children to the predictability of social and nonsocial toys. J Autism Dev Disord 1980;10: $51-57$

119. Riguet C, Taylor N, Benaroya S, Klein E. Play in autistic, Down's, and normal children of equivalent mental age. J Autism Dev Disord 1981;11: 439-488 227

120. Charman T, Baron-Cohen S. Brief report: prompted pretend play in autism. J Autism Dev Disord 1997;27:325-332

121. Stone W, Lemanek K, Fishel P, Fernandez M, Altemeier W. Play and imitation skills in the diagnosis of autism in young children. Pediatrics 1990;86:267-272

122. Libby S, Powell S, Messer D, Jordan R. Spontaneous play in children with autism: a reappraisal. J Autism Dev Disord 1998;28:487-497

123. 25th Annual Report to Congress on the Implementation of the Individuals with Disabilities Education Act. Office of Special Education and Rehabilitative Services. Washington, DC: US Department of Education; $\mathrm{xxxx}^{\mathrm{Q} 28}$

124. Early Intervention in North Carolina. Data from the Infant Toddler Program. Available at: http:// www.ncei.org/ei/pdf/EIProfile2002.pdf. Accessed $\mathrm{xxx} \mathrm{xx}, 2006^{\mathrm{Q} 29}$

125. American Academy of Pediatrics. Developmental surveillance and screening of infants and young children. Pediatrics 2001;108:192-196 


\section{Author Query Form (SSL/00272)}

\section{Special Instructions: Author please write responses to queries directly on proofs and then return back.}

Q1: Is the word "million" missing here?

Q2: "10,000" the correct number here?

Q3: Please check to see that semicolons divide items correctly. Original was a bit unclear.

Q4: OK to move citation numbers here after main idea found in all references?

Q5: Can you provide a citation number here and full information in the reference list for this source?

Q6: OK to move citation numbers here after main idea found in all references?

Q7: OK to have changed "the current manuscript" to "this article"?

Q8: Betsy: I deleted a bunch of this because we had discussed it earlier in the review of methods/intro and it seemed redundant here. GB

Q9: OK to insert "at" before "first"?

Q10: Does this early intervention system have a name, or should it have caps because that is its name? Can you specify what Part $\mathrm{C}$ refers to?

Q11: Cannot find a title to match the journal "Current Direc Psych Sci" (in reference 4 "Gernsbacher, Dawson, Goldsmith, 2004").

Q12: Cannot find a title to match the journal "Analysis Intervent Develop Disab" (in reference 8 "Fenske, Zalenski, Krantz, McClannahan, 1985").

Q13: Please check authors-is "Wood" missing a first initial, or is it "Wood BS" ?

Q14: Cannot find a title to match the journal "J Dev Learn Disord" (in reference 68 "Greenspan, Wieder, 1997").

Q15: Reference has only first page number. Please provide the last page number if article is longer than one page. (in reference 69 "Carpenter, Nagell, Tomasello, 1992").

Q16: Cannot find a title to match the journal "Gesture" (in reference 71 "Jones, Zimmerman, 2003").

Q17: The reference 78 "Baranek, Watson, Crais, Alcott, 2001" is not cited in the text. Please add an in-text citation or delete the reference. Also, please complete publication information.

Q18: Cannot find a title to match the journal "Develop Psychopath" (in reference 85 "Mundy, 1995").

Q19: Can you update publication information for reference 87? 
Q20: Cannot find a title to match the journal "Br J Develop Psychol" (in reference 95 "Leekam, Baron-Cohen, Perrett, Milders, Brown, 1997").

Q21: Cannot find a title to match the journal "Topics Lang Disord" (in reference 103 "Tsatsanis, 2004").

Q22: The reference 110 "Schreck, Williams, Smith, 2004" is not cited in the text. Please add an in-text citation or delete the reference.

Q23: Please insert journal name before year of publication. Could not find in PubMed.

Q24: Cannot find a title to match the journal "Topics Lang Disord" (in reference 114 "Thal, 1991").

Q25: "Et al" found after fewer than 3 authors. Please check reference (in reference 118 "Yoder, et al, 1995").

Q26: Cannot find a title to match the journal "J Early Intervention" (in reference 118 "Yoder, et al, 1995").

Q27: Please check reference. Do you mean: Riguet CB, Taylor N, Benaroya S, Klein LS. Symbolic play in autistic, Down's, and normal children of equivalent mental age. J Autism Dev Disord 1981; 11:439-448?

Q28: Please provide date of publication.

Q29: AU: Please provide date the Web site in reference 126 was accessed.

Q30: AU: Please provide a complete mailing address for the corresponding author.

Q31: Au: Per journal style, reference citations are not allowed in headings. Please review suggested sentence and modify as needed. 


\title{
Instructions to Contributors
}

Dear Contributor:

Enclosed in this document please find the page proofs, copyright transfer agreement (CTA), and offprint order form for your article in the Seminars in Speech \& Language, Volume 27, Number 3, 2006. Please print this document and complete and return the CTA and offprint form, along with corrected proofs, within 72 hours.

1) Please read proofs carefully for typographical and factual errors only; mark corrections in the margins of the proofs in pencil. Answer (on the proofs) all editor's queries written in the margins of the proofs. Check references for accuracy. Please check on the bottom of the 1st page of your article that your titles and affiliations are correct. Avoid elective changes, as these are costly and time consuming and will be made at the publisher's discretion.

2) Please pay particular attention to the proper placement of figures, tables, and legends. Please provide copies of any formal letters of permission that you have obtained.

3) Please return the corre cted proofs, signed copyright transfer agreement, and your offprint order form, with the black and white or color prints of figures, if you received any.

4) As a contributor to this journal you will receive one copy of the journal, at no charge.

- If you wish to order offprints, please circle the quantity required (left column) and the number of pages in your article. If you wish to order additional copies of the journal please enter the number of copies on the indicated line.

- If you do not want to order offprints or journals simply put a slash through the form, but please return the form.

Please send all materials back via overnight mail, within 72 hours of receipt, to:

\author{
Xenia Golovchenko \\ Production editor \\ Thieme Medical Publishers \\ 77 Gregory Blvd. \\ Norwalk, CT 06855 \\ Tel: $845-548-8127$ \\ Fax: 203-857-4996 \\ E-mail: xeniag@optonline.net
}

\section{Please do not return your materials to the editor, or the compositor.}

Please note: Due to a tight schedule, if the publisher does not receive the return of your article within 7 days of the mail date (from the compositor), the publisher reserves the right to proceed with publication without author changes. Such proofs will be proofread by the editor and the publisher.

Thank you for your contribution to this journal.

Xenia Golovchenko, Production Editor, Journal Production Department

Thieme Medical Publishers, Inc. 
Thieme Medical Publishers, Inc. (the "Publisher") will be pleased to publish your article (the "Work") entitled in the Seminars in Speech \& Language, Volume 27, Number 3, 2006.

The undersigned Author(s) hereby assigns to the Publisher all rights to the Work of any kind, including those rights protected by the United States Copyright laws.

The Author(s) will be given permission by the Publisher, upon written request, to use all or part of the Work for scholarly or academic purposes, provided lawful copyright notice is given.

If the Work, subsequent to publication, cannot be reproduced and delivered to the Author(s) by the publisher within 60 days of a written request, the Author(s) is given permission to reprint the Work without further request.

The Publisher may grant third parties permission to reproduce all or part of the Work. The Author(s) will be notified as a matter of courtesy, not as a matter of contract. Lawful notice of copyright always will be given.

Check appropriate box below and affix signature.

[ ] I Sign for and accept responsibility for transferring copyright of this article to Thieme Medical Publishers, Inc. on behalf of any and all authors.

Author's full name, degrees, professional title, affiliation, and complete address:

[ ] I prepared this article as part of my official duties as an employee of the United States Federal Government. Therefore, I am unable to transfer rights to Thieme Medical Publishers, Inc. 
Order Form for Offprints and additional copies of the Seminars in Speech and Language

(Effective October 2005)

Please circle the cost of the quantity/page count you require (orders must be in increments of 100)

\begin{tabular}{|r|r|r|r|r|r|}
\cline { 2 - 6 } \multicolumn{1}{c|}{} & \multicolumn{5}{|c|}{ Pages in Article/Cost } \\
\hline Quantity & $\mathbf{1 ~ t o} 4$ & $\mathbf{5}$ to 8 & $\mathbf{9}$ to 12 & $\mathbf{1 3}$ to 16 & $\mathbf{1 7}$ to 20 \\
\hline $\mathbf{1 0 0}$ & $\$ 198$ & $\$ 317$ & $\$ 440$ & $\$ 578$ & $\$ 693$ \\
\hline $\mathbf{2 0 0}$ & $\$ 277$ & $\$ 444$ & $\$ 615$ & $\$ 809$ & $\$ 970$ \\
\hline $\mathbf{3 0 0}$ & $\$ 356$ & $\$ 570$ & $\$ 791$ & $\$ 1,041$ & $\$ 1,247$ \\
\hline $\mathbf{4 0 0}$ & $\$ 396$ & $\$ 634$ & $\$ 879$ & $\$ 1,156$ & $\$ 1,386$ \\
\hline $\mathbf{5 0 0}$ & $\$ 446$ & $\$ 713$ & $\$ 989$ & $\$ 1,301$ & $\$ 1,559$ \\
\hline $\mathbf{1 0 0 0}$ & $\$ 792$ & $\$ 1,267$ & $\$ 1,758$ & $\$ 2,313$ & $\$ 2,772$ \\
\hline
\end{tabular}

Volume/Issue \#: Page Range (of your article):

Article Title:

MC/Visa/AmEx No: Exp. Date:

Signature:

Name:

Address:

City/State/Zip/Country:

Corresponding author will receive one complimentary copy of the issue in which the manuscript is published.

Number of additional copies of the journal, at the discounted rate of $\$ 20.00$ each:

\section{Notes}

1. The above costs are valid only for orders received before publication of the issue. Please return the completed form, even if your institution intends to send a Purchase Order (the P.O. may sometimes be supplied after the issue has been printed).

2. Orders from outside the U.S. must be accompanied by payment.

\section{A shipping charge will be added to the above costs.}

4. Reprints are printed on the same coated paper as the journal and side-stapled.

5. For larger quantities or late orders, please contact reprints dept. $\quad$ Phone: $+1(212) 584-4662$

Fax: +1(212) 947-1112

E-mail: reprints@thieme.com

As an added benefit to all contributing authors, a discount is offered on all Thieme books. See below for details or go to $w w w$.thieme.com 
As a Thieme author you are entitled to a $\mathbf{2 5 \%}$ discount for existing books and a $35 \%$ discount for forthcoming books.

We selected two books that might be of interest for you:

\section{forthcoming! $35 \%$ discount

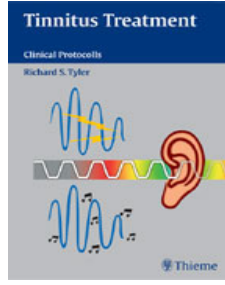 \\ Tinnitus Treatment: Clinical Protocols \\ Richard Tyler, PhD, \\ Professor, Director of Audiology, \\ Department of Otolaryngology, \\ University of lowa Hospitals and Clinics, \\ lowa City, lowa}

Beginning with the latest neurophysiological and psychological models of tinnitus, the book goes on to cover evaluation tools; counseling options and methods; treatment with hearing aids, wearable and nonwearable noise generators, and music; tinnitus-related insomnia; and quality-of-life issues. You will also find sample handouts to allow for effective communication with patients. Highly experienced clinicians from around the world give you the practical strategies you need to confidently apply each therapeutic approach. With key clinical information for implementing all current therapies, Tinnitus Treatment: Clinical Protocols is an essential professional resource.

Estimate Publication 2006

256 pp., 42 illus., hardcover ISBN 1-58890-181-5
$\$ 59.95 \$ 38.97$

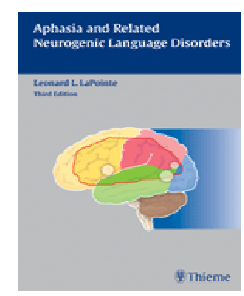

$25 \%$ discount

\section{Aphasia and Related Neurogenic Language Leonard L. LaPointe, PhD, MD \\ Francis Eppes Professor of Communication Disorders, Florida State University, \\ Tallahassee, FL (Editor) \\ Third Edition}

Here is the completely updated third edition of the classic text on aphasia, covering key developments in treating language disruptions caused by stroke and other types of brain damage or trauma. From the latest neurobiological aspects, to social and group models of intervention and rehabilitation, this book is allinclusive. The text begins with the primary types of aphasia and goes on to cover pathophysiology, nature and differentiating features, evaluation, and treatment principles. Blending traditional approaches to aphasia impairment with current World Health Organization models, and including contributions by some of the leading experts in the field, this book is a must for speechlanguage pathologists, neuropsychologists, neurologists, and audiologists.

2005, 296 pp., 27 illus., hardcover, ISBN 1-58890-226-9

\section{See all our books at}

Thieme Books

Thieme Author order form

For faster service, call TOLL-FREE 1-800-782-3488 or fax this order form to 212-947-1112

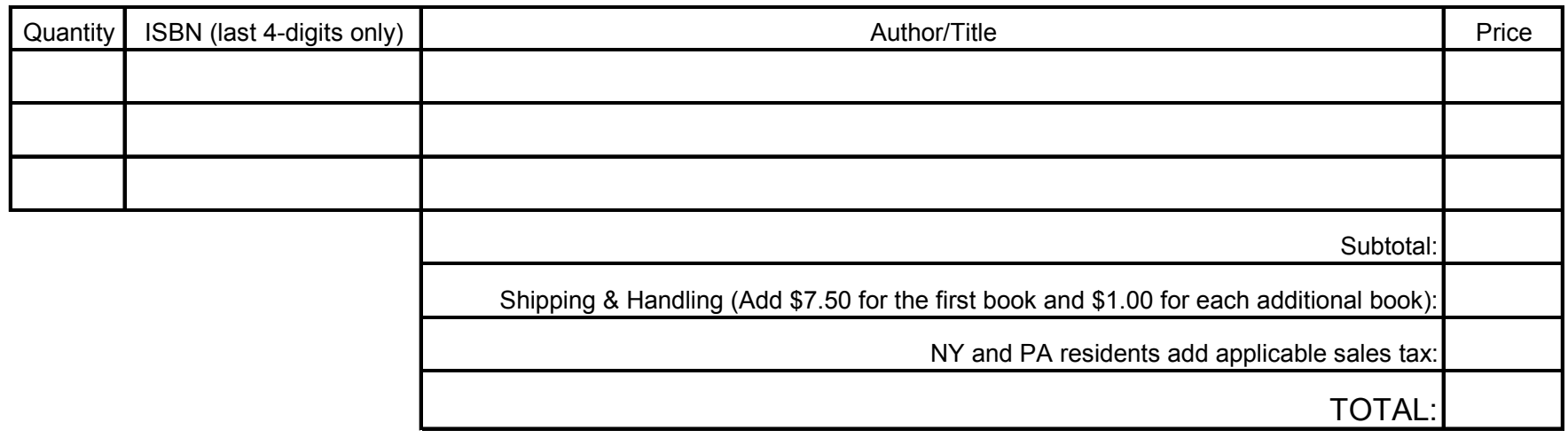

Enclosed is my check for $\$$

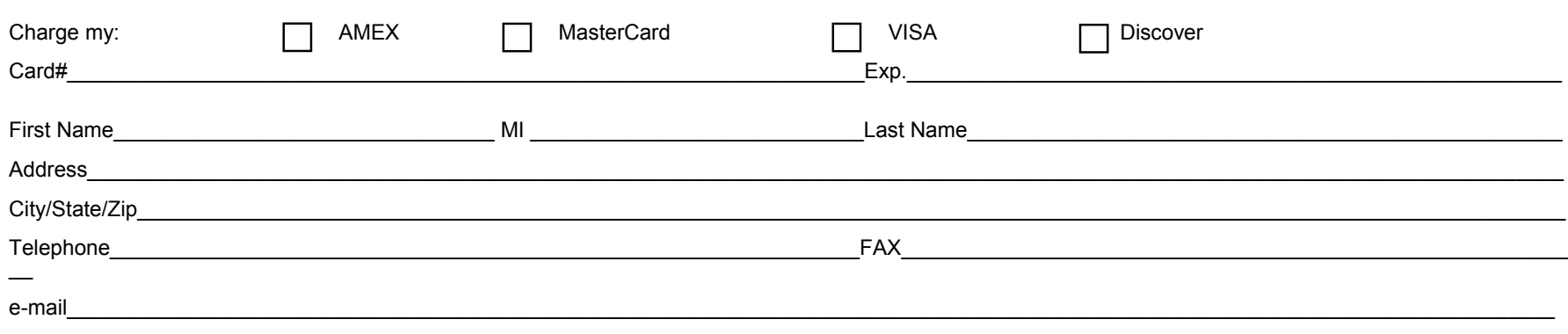

Signature 